\title{
Novel nanoformulation of disulfiram with bacterially synthesized copper oxide nanoparticles for augmenting anticancer activity: an in vitro study
}

\author{
Marwa M. Abu-Serie ${ }^{1 *}$ and Marwa Eltarahony ${ }^{2}$
}

\author{
*Correspondence: \\ marwaelhedaia@gmail.com \\ 'Medical Biotechnology \\ Department, \\ Genetic Engineering \\ and Biotechnology \\ Research Institute (GEBRI), \\ City of Scientific Research \\ and Technological \\ Applications (SRTA-City), \\ New Borg El-Arab City, \\ Alexandria 21934, Egypt \\ Full list of author information \\ is available at the end of the \\ article
}

\begin{abstract}
Background: Disulfiram (DS), in the presence of copper (Cu), exhibited potent broad anticancer activity. However, its clinical application is limited due to the poor solubility and stability. Hence, a novel nanocombination of DS with bacterially synthesized copper oxide nanoparticles (CUO NPs) was prepared herein to improve the anticancer efficacy of the typical DS-Cu complex. Our design utilized the nanocharacterization and prooxidant effect-mediated anticancer activity of CuO NPs which may lead to enhanced cellular uptake and thus improved anticancer efficacy of this unique nanocomplex.
\end{abstract}

Results: The characterized DS-CuO NPs exhibited high stability in serum and the strongest selective anticancer activity, with the lowest half-maximum inhibitory concentration $\left(I C_{50}<15 \mathrm{nM}\right)$, against human breast, lung and liver cancer cells, by $>10$ fold, compared to DS-Cu, CuO NPs and Cu. Importantly, DS-CuO NPs revealed better synergistic anticancer effect and higher cellular uptake than DS-Cu. Moreover, this novel nanocomplex showed higher prooxidant effect-mediated apoptosis and antimetastatic potential. This was accomplished by elevating cellular reactive species content with inhibiting the antioxidant defenders (functional marker of cancer stem cells (aldehyde dehydrogenase) and nuclear factor erythroid 2-related factor2), matrix metallopeptidase 9 and NF-kB as well as enhancing p53 expression.

Conclusion: All of the aforementioned findings verified that this novel nanocomplex was capable of improving the therapeutic index of the conventional DS-Cu complex. The potent selective anticancer activity of this promising nanomedicine merits further investigation, as a separate future study, using animal models as preliminary step before its clinical application.

Keywords: Disulfiram, Copper oxide nanoparticles, Disulfiram-copper oxide nanoparticles, Cellular uptake, Anticancer

(c) The Author(s) 2021. Open Access This article is licensed under a Creative Commons Attribution 4.0 International License, which permits use, sharing, adaptation, distribution and reproduction in any medium or format, as long as you give appropriate credit to the original author(s) and the source, provide a link to the Creative Commons licence, and indicate if changes were made. The images or other third party material in this article are included in the article's Creative Commons licence, unless indicated otherwise in a credit line to the material. If material is not included in the article's Creative Commons licence and your intended use is not permitted by statutory regulation or exceeds the permitted use, you will need to obtain permission directly from the copyright holder. To view a copy of this licence, visit http:// creativecommons.org/licenses/by/4.0/. The Creative Commons Public Domain Dedication waiver (http://creativecommons.org/publicdomain/zero/1.0/) applies to the data made available in this article, unless otherwise stated in a credit line to the data. 


\section{Background}

Cancer is a leading cause of death and a major impediment to increasing life expectancy. According to GLOBOCAN 2020, lung, liver and female breast cancers remain significant causes of cancer death, accounting for $18 \%, 8.3 \%$ and $6.9 \%$, respectively (Sung et al. 2020). Hence, our current study focused on these cancer types. Chemotherapy is typically the first line for cancer treatment. However, the efficacy of the current chemotherapeutic drugs is limited, particularly in late-stage tumors. Repurposing approved drugs is a promising approach because it reduces risks with saving time and money, facilitating clinical translation.

Disulfiram (DS) which is approved by the Food and Drug Administration (FDA) for the treatment of alcoholism under the brand names Antabuse ${ }^{\circledR}$ or Antabus ${ }^{\circledR}$, exhibited broad and efficient anticancer activity (Xu et al. 2020). DS causes cancer cell death by upregulating reactive oxygen species (ROS) production, proapoptotic proteins (p53 and Bax) and proteasome inhibition (Meraz-Torres et al. 2020). The latter prevents the degradation of inhibitors of cyclins and cyclin-dependent kinases resulting in cell cycle arrest and inhibits NF-kB which mediates the expression of key genes of oncogenesis, angiogenesis and metastasis (Almond and Cohen 2002). DS also blocks angiogenesis and invasion through inactivation of collagenase IV and matrix metallopeptidases (MMPs) (Meraz-Torres et al. 2020).

Based on previous studies, this anticancer effect of DS is potentiated in the presence of copper $\left(\mathrm{Cu}^{2+}\right)$ (Meng et al. 2021; Xu et al. 2020; Wang et al. 2020; Chang et al. 2020). Intracellular copper plays a crucial role in triggering the generation of excessive ROS that mediate cancer death. DS is a bivalent metal ion chelator that strongly interacts with $\mathrm{Cu}^{2+}$ to form mixed disulfides (DS-Cu), which overcome the limited $\mathrm{Cu}$ transport into cancer cells, disrupt gene transcription and vital protein function and generate more ROS (Meraz-Torres et al. 2020; Duan et al. 2014; Brar et al. 2004). It is worth noting that the clinical use of DS or its chelating complex with $\mathrm{Cu}$ (copper diethyldithiocarbamate)) as cancer treatment is limited due to its poor bioinstability in the bloodstream and bioavailability. As a consequence, the need for a long-circulating nanodrug-delivery system to protect DS, improve bioavailability and enable targeted delivery remains unabated (Najlah et al. 2021; Chen et al. 2018; Wehbe et al. 2017).

A wide range of nanobased drug-delivery systems for DS and its complex such as micelles, liposomes, lipid-based NPs and polymeric NPs were investigated. However, efficient drug delivery remains a challenge for clinical application (Najlah et al. 2021; Chen et al. 2018). Hence, in this study, the nanoformulated DS-Cu complex was prepared using a novel, cost-effective and simple method by directly chelating DS with bacterially synthesized copper oxide nanoparticles (CuO NPs). The green biosynthesis of metallic NPs is an ecofriendly, cheap, clean, safe and time efficient method that overcomes the drawbacks of physical and chemical techniques (Eltarahony et al. 2021). Herein, for the first time, Streptomyces pluricolorescences EM4 was used as bionanofactory for green bioproduction of $\mathrm{CuO}$ NPs. The main objective of this novel study is nanoformulation of DS chelating complex with improving its solubility and biostability as well as achieving more potent selective anticancer efficacy against breast, lung and liver cancer cells than classic DS-Cu. The anticancer potency was investigated via assessment 
of apoptosis, fold change in ROS, cell migration and key mediators of redox-mediated oncogenesis at gene and protein levels.

\section{Materials and methods \\ Materials}

Dulbecco's modified Eagle's medium (DMEM), Roswell Park Memorial Institute (RPMI) 1640 medium, and fetal bovine serum (FBS) were purchased from GIBCO (MA, USA). Disulfiram and copper II nitrate were obtained from Acros Organics (New Jersey, USA) while nuclear stains and retinal from Sigma-Aldrich (MI, USA). Molecular reagents and kits were purchased from Thermo Fisher Scientific (MA, USA) and other colorimetric assay (MMP9, ALDH 1A, Nrf2) kits and IKB antibody from Abcam (Cambridge, UK).

\section{Instruments}

Atomic absorption spectroscopy (Anylatik Jena, Germany) was used for quantification of CuNPs. The characterization of the formed nanocomplex of DS-Cu was performed using Zetasizer Nano ZS (Malvern, UK), EDX (JEOL JEM-1230, Japan) and XRD (Bruker MeaSrv (D2-208219), Germany), TEM (JEOL JEM-1230-Japan) and SEM (JEOL, model JSM-6460LV, Japan). MTT assay was measured using ELISA plate reader (BMG Labtech, Germany) and phase contrast microscope (Olympus, Japan). Apoptosis was analyzed using flow cytometry (Partec, Germany) and fluorescence microscope (Olympus, Japan) as well as real-time PCR detection system (BIO-RAD, USA). Cellular ROS was quantified using spectrofluorometry (BMG Labtech, Germany).

\section{Methods}

\section{Bacterial biosynthesis of CuO NPs}

The bacterial bionanofactory Streptomyces pluricolorescence EM4 was isolated from Marriott Lake sediment (Alexandria, Egypt); exhibiting versatile and characteristic metabolic capabilities. It was submitted to GenBank under the accession number KY964509. The cylinders disks ( $9 \mathrm{~mm}$ in diameter) were punctured from the sporulated culture of EM4 strains by sterile cork-borer and inoculated into starch nitrate broth. This medium consisting of $10 \mathrm{~g}$ soluble starch, $2 \mathrm{~g} \mathrm{KNO}_{3}, 100 \mathrm{~g} \mathrm{NaCl}, 1 \mathrm{~g} \mathrm{~K}_{2} \mathrm{HPO}_{4}, 0.5 \mathrm{~g} \mathrm{MgSO}_{4} .7 \mathrm{H}_{2} \mathrm{O}$, $3 \mathrm{~g} \mathrm{CaCO}_{3}$ and $1 \mathrm{ml}$ of trace elements solution $\left(0.1 \mathrm{~g} \mathrm{FeSO}_{4} \cdot 7 \mathrm{H}_{2} \mathrm{O}, 0.1 \mathrm{~g} \mathrm{MnCl}{ }_{2} \cdot \mathrm{H}_{2} \mathrm{O}\right.$, $0.1 \mathrm{~g} \mathrm{ZnSO}_{4} \cdot 7 \mathrm{H}_{2} \mathrm{O}$ ), supplemented by $2 \mathrm{mM}$ of $\mathrm{Cu}\left(\mathrm{NO}_{3}\right)_{2}$ as a precursor of $\mathrm{CuO} \mathrm{NPs}$ (Eltarahony et al. 2021). The culture was incubated under orbital shaking conditions $(150 \mathrm{rpm})$ at $30{ }^{\circ} \mathrm{C}$ for $96 \mathrm{~h}$. At the same time, two control experiments, media with metal precursors without bacterial inoculum and media with bacterial inoculum without metal precursor, were incubated in exact conditions. During the incubation period, the bioconversion of $\mathrm{Cu}$-precursor to $\mathrm{CuO}$ NPs, was observed by the change in biomass color. For NPs extraction, the microbial pellets containing $\mathrm{CuO}$ NPs were collected by centrifugation at $11,000 \times g$ for 20 min and washed severally by doubled distilled $\mathrm{H}_{2} \mathrm{O}$ and $70 \%$ ethyl alcohol to eliminate media residuals. The $\mathrm{CuO}$ NPs were extracted from the cell as procedure described previously by Eltarahony et al. (2018). Briefly, the bacterial pellets were disrupted by suspending them in Tris HCl-sucrose-EDTA (TSE) lysis buffer thereby sonication at $60-80 \%$ amplitude for 20 min with $0.6 \mathrm{~s}$ pulse rate. The 
extracted $\mathrm{CuO}$ NPs were subjected for the following analyses after centrifugation, washing and drying steps (Eltarahony et al. 2018).

\section{Nanocombination of DS with the biosynthesized CuO NPs}

After freezing-drying the above-prepared $\mathrm{CuO}$ NPs, it was quantified using atomic absorption spectroscopy. Then equimolar solution of DS and CuO NPs were prepared and mixed well forming a greenish brown color of DS-CuO nanocomplex (DS-CuO NPs), in parallel with the preparation of the traditional combination of DS with copper (DS-Cu). The nanocharacterization of this formed complex was verified using the following analytical techniques.

\section{Characterization techniques}

Size and zeta potential of $\mathrm{CuO}$ NPs and nanocomplex were measured by Zetasizer Nano ZS and the data were analyzed by Zetasizer software 6 . In addition, serum stability of DS-CuO NPs in phosphate buffer saline (PBS) containing 50\% fetal bovine serum, at $37^{\circ} \mathrm{C}$, was detected by measuring its size during $72 \mathrm{~h}$. The compositional characteristics of the as-prepared $\mathrm{CuO}$ NPs were detected with EDX operating at an accelerated voltage of $200 \mathrm{kV}$. The structural features of $\mathrm{CuO}$ NPs and DS-CuO NPs were examined through X-ray diffractometer with $\mathrm{Cu} K \alpha$ radiation tube $(\lambda=1.5406 \AA)$ operated at a voltage of $30 \mathrm{kV}$, with scan rate of $0.02^{\circ} / \mathrm{s}$ in $2 \theta$ angular range of $2-80^{\circ}$. Then, JCPDS was used to analyze the data. The morphological characteristics of the as-prepared nanocomplex were verified by TEM and SEM.

\section{In vitro anticancer assessment of DS-CuO NPs against breast, lung and liver cancer cells} Cytotoxicity determination in human cancer cells

Anticancer activity of the conventional complex and its nanoformulation was assayed using three human cancer types. Triple-negative breast cancer cell line (MDA-MB 231) and liver cancer cell lines (Huh7 and HepG2) were cultured in RPMI-1640 while lung cancer cell line (A549) was cultured in DMEM. Both media were supplemented with $10 \%$ fetal bovine serum. All cancer cells $\left(5 \times 10^{3}\right.$ cells/well $)$ were seeded in cell culture 96-well plates. After $24 \mathrm{~h}$ of cell attachment, serial concentrations of DS-CuO NPs, DS$\mathrm{Cu}$ complex, DS, $\mathrm{CuO}$ NPs, $\mathrm{CuO}$ and copper nitrate $(\mathrm{Cu})$ were incubated with four cancer cell lines for $48 \mathrm{~h}$ at $37{ }^{\circ} \mathrm{C}$ in $5 \% \mathrm{CO}_{2}$ incubator. The percentage of growth inhibition in the treated wells was quantitatively determined by MTT method (Mosmann 1983). The $\mathrm{IC}_{50}$ values were estimated using GraphPad Prism 6. In addition, cellular morphological changes before and after treatment were investigated using phase contrast inverted microscope with a digital camera. Moreover, CI of DS-CuO NPs and DRI of $\mathrm{DS}$ and $\mathrm{CuO}$ in this nanocombination were estimated to evaluate the extent of its synergistic anticancer activity relative to DS-Cu.

\section{Cytotoxicity determination of the active complex and its NPs in human blood mononuclear cells}

Human mononuclear cells (HMNCs) were isolated from blood which was collected from healthy volunteers. This is in accordance with the guidelines of the Research Ethical Committee, Faculty of Medicine, Alexandria University (Approval no. 0305246) and the 
recommendations of the National Health and Medical Research Council policies and the Ministry of Health and Population, Egypt. HMNCs were obtained using Ficoll-Hypaque density gradient centrifugation method, as previously described (Ferrante and Thong 1980). Briefly, heparinized blood samples were carefully layered on Ficoll-Hypaque then centrifuged at $2000 \mathrm{rpm}$ for $30 \mathrm{~min}$. The undisturbed HMNCs layer was carefully collected and centrifuged twice at $1650 \mathrm{rpm}$ for $5 \mathrm{~min}$ then cell pellet was suspended in RPMI-1640 medium containing 10\% FBS and counted using trypan blue exclusion method. HMNCs $\left(10^{4}\right.$ cells/well) were seeded in 96 -well sterile round bottom plate then serial concentrations of DS-CuO NPs and DS-Cu complex were added. After $48 \mathrm{~h}$ incubation, the viability of HMNCs was determined using MTT method, as described above, to estimate $\mathrm{IC}_{50}$. Moreover, the selectivity indexes (SI) of DS-CuO NPs and DS-Cu were calculated as the ratio of $\mathrm{IC}_{50}$ for $\mathrm{HMNCs}$ to $\mathrm{IC}_{50}$ for each human cancer cell line.

\section{Cellular uptake of $\mathrm{Cu}$ and $\mathrm{CuONPS}$}

After seeding MDA-MB 231, A549 and Huh7 in $25 \mathrm{~cm}^{2}$ T-flasks $\left(1 \times 10^{6}\right.$ cells per flask $)$ and $24 \mathrm{~h}$ cell attachment, $12 \mu \mathrm{g}$ (maximum safe dose) of DS-CuO NPs, DS-Cu complex, $\mathrm{CuO}$ NPs and $\mathrm{Cu}$ were added. The untreated and treated cells were harvested after $2 \mathrm{~h}$ then counted, washed and digested. The cellular contents of $\mathrm{Cu}$ and $\mathrm{CuO}$ were measured by atomic absorption spectroscopy and expressed as percentage relative to original added amounts.

\section{Flow cytometry and fluorescence microscope for investigating the apoptotic effect of the tested complexes}

After $48 \mathrm{~h}$ incubation of both complexes with MDA-MB231, A549, Huh7 and HepG2, at the corresponding $\mathrm{IC}_{50}$ of DS-CuO NPs for each cell line, cells were trypsinized and washed then incubated with FITC-annexin V/propidium iodide (PI) for $15 \mathrm{~min}$. The apoptosis-dependent anticancer effect was determined by quantification of annexinstained apoptotic cells using the FITC signal detector (FL1) against the phycoerythrin emission signal detector (FL2) of flow cytometry. Meanwhile, fluorescence microscope was used after staining the adherent treated breast, lung and liver cancer cells with ethidium bromide and acridine orange $(\mathrm{EB} / \mathrm{AO})$.

\section{Wound healing migration assay}

After breast, lung and liver cancer cells reaching 90\% confluence, cells were scratched and treated with safe doses of complexes (at $\sim 1.5 \mathrm{nM}$ ). The wound area was photographed and calculated by image $\mathrm{j}$ software for estimating the inhibition migration percentages in the treated wells relative to untreated wells at 0 and $24 \mathrm{~h}$.

\section{QPCR measurement of the effect of the studied complexes on $p 53$ and NF-KB expression}

The total RNA of the treated and untreated wells was extracted and the CDNA was synthesized using RNA purification and cDNA synthesis kits, respectively. The expression levels of target genes were measured using SYBR green master mix and specific primers. The following primers were forward $5^{\prime}$-ATGTTTTGCCAACTGGCCAAG-3, reverse: 5'-TGAGCAGCGCTCATGGTG-3' for p53 and forward: 5'-TCAAGATCTGCCGAC TGAAC-3', reverse: $5^{\prime}$-CCTCTTTCTGCACCTTGTCA-3' for NF- $\mathrm{kB}$. The fold change 
in the expression of target genes, relative to the untreated control cells, was calculated via $2^{-\Delta \Delta C q}$ method.

\section{Measurement of the increment in intracellular ROS generation}

The cellular ROS level was determined by incubation of the untreated and treated cancer cells with dichloro-dihydro-fluorescein diacetate (DCFH-DA) for $48 \mathrm{~h}$. DCFDA is oxidized by cellular ROS to fluorescent DCF, which was assessed using spectrofluorometry at $480 \mathrm{~nm}$ excitation and $530 \mathrm{~nm}$ emission. Then relative fold change in ROS content in the treated cells relative to the untreated was calculated.

\section{Determination of inhibitory potency of both complexes on MMP9 activity, ALDH1A activity and Nrf2 transcriptional activation}

The activity of MMP9 and ALDH1A were detected in the lysates of complexes-treated cancer cells, relative to the untreated cells, using colorimetric assay kits. In ALDH1A assay, retinal was used as substrate due to the affinity of ALDH1A1 and ALDH1A3, which are predominant enzymes in the selected cancer cell lines. Also, the percentage inhibition of Nrf2 transcription of detoxifying enzyme genes in the untreated and treated cells was quantified according to manufacturing instructions.

\section{Immunohistochemistry staining of IKB}

Briefly, after $48 \mathrm{~h}$ incubation of human cancer cell lines with the studied complexes, at the corresponding $\mathrm{IC}_{50}$ of DS-CuO NPs, cells were trypsinized, washed and fixed in paraformaldehyde. The fixed cells were dehydrated (using graded ethanol concentrations) and immersed in xylene; cells were collected by centrifugation at each step. Then impregnated in melted paraffin forming solid paraffin blocks. The latter were cut into 3-5 $\mu \mathrm{m}$ thick sections and transferred into positively charged slides. After drying, dewaxing, rehydrating slides, microwave heating in citrate buffer and washing, primary IKB antibody (1:400) was added. After overnight incubation, horseradish peroxidaseconjugated secondary antibody then substrate $\left(3,3^{\prime}\right.$ diaminobenzidine) were added and the developing colored product was detected to estimate the percentage of immunostained cells by CellSens imaging analysis software of the phase contrast microscope.

\section{Statistical analysis}

All data are presented as mean \pm standard error of the mean (SEM). Tukey's post hoc ANOVA and unpaired two-tail Student's $t$ tests were used for multiple comparisons and two groups comparisons, respectively, using SPSS 16.0. Statistical differences were expressed as $p$ value $<0.05^{*},<0.005^{* * *},<0.001^{* * * *}$.

\section{Results}

Biosynthesis and physicochemical properties of CuO NPs and DS-CuO NPs

The biosynthesis of functionalized $\mathrm{CuO}$ NPs was initially validated by changing the color of S. pluricolorescence EM4 culture from pale green to faint brown after incubation with copper nitrate, a precursor of $\mathrm{CuO}$ NPs. Comparatively, no obvious changes occurred in the control cultures, revealing that $\mathrm{Cu}$-precursor was successfully bioconverted into its corresponding NPs. The yield of extracted $\mathrm{CuO}$ NPs was 
$6 \mathrm{mg} / 100 \mathrm{ml}$ culture that quantified using atomic absorption. Following the preparation of an equimolar water soluble DS-CuO nanocomplex $(0.5 \mathrm{mM})$, the characteristic and structural verification of biosynthesized $\mathrm{CuO}$ NPs and this nanocomplex were demonstrated in the subsequent physicochemical analyses.

Size and zeta potential of $\mathrm{CuO}$ NPs were $143.07 \pm 1.13 \mathrm{~nm}$ and $-27.5 \pm 0.50 \mathrm{mV}$, respectively, while that of DS-CuO NPs were $235.05 \pm 4.15 \mathrm{~nm}$ and $-26.21 \pm 0.78 \mathrm{mV}$, respectively (Additional file 1: Fig. S1). Particle sizes of both $\mathrm{CuO}$ NPs and DS-CuO NPs have acceptable polydispersity indexes (PDI, 0.222 and 0.119 , respectively). Regarding, the stability of nanocomplex in serum, Fig. 1a did not show any marked changes in particle size, without precipitation, during $72 \mathrm{~h}$, indicating good stability of DS-Cu NPs. The water solubility of the prepared DS-CuO NPs was $2 \mathrm{mg} / \mathrm{ml}$.

Energy-dispersive X-ray spectrometer (EDX) pattern of bacterially synthesized NPs affirmed the existence of potent signals of $\mathrm{Cu}$ and $\mathrm{O}$, by $66.93 \%$ and $33.07 \%$, respectively, at their corresponding surface energies $8.0 / 0.9$ and $0.5 \mathrm{keV}$, respectively (Fig. 1b). This phase identification was further assured by X-ray diffractometer (XRD), which revealed a series of distinguishable peaks at $2 \theta=32.4^{\circ}, 38.5^{\circ}, 45.5^{\circ}, 53.2^{\circ}$ and $61.5^{\circ}$, corresponding to (110), (111), (- 112), (020) and (-113) Bragg's reflection, respectively (Fig. 1c). Such peaks position with their intensities matched the monoclinic cubic phase of $\mathrm{CuO}$ with the standard spectrum (Joint Committee on Powder Driven Standards (JCPDS) file no. 01-089-5896). In either EDX or XRD of the biosynthesized $\mathrm{CuO}$ NPs, there were no obvious peaks for bacterial culture traces. The XRD diffractogram of nanometal complex disclosed a series of distinct peaks at $2 \theta=12.33^{\circ}, 15.47^{\circ}, 18.50^{\circ}, 19.77^{\circ}$ and $22.24^{\circ}, 25.08^{\circ}, 27.36^{\circ}, 29.79^{\circ}$ and $30.947^{\circ}$ with reflection planes (-101), (-111), (020), (-112) and (-121), (232), (230), (- 220) and (333), respectively (Fig. 1c). These diffraction peaks and planes were found to correspond to the triclinic phase of copper thiourea sulfate hydrate (JCPDS file no. 52-0501). Moreover, micrographs of transmission and scanning electron microscopes

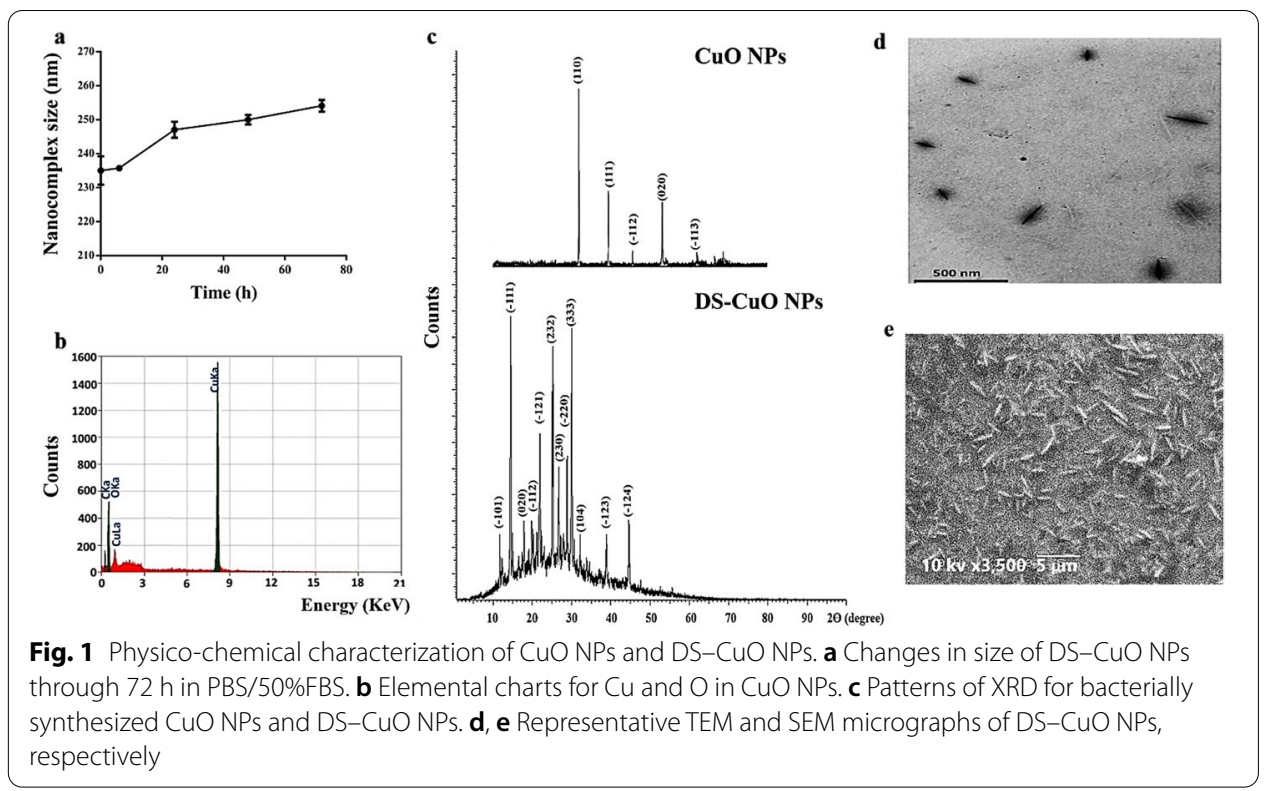


(TEM and SEM, respectively) revealed $2 \mathrm{D}$ and 3D, respectively, of rod, needle or spindle shaped DS-CuO NPs (Fig. 1d, e).

\section{Selective growth inhibitory efficacy of DS-CuO NPs compared to the typical DS-Cu complex on breast, lung and liver cancer cells}

The MTT assay was primarily used to assess the anticancer potency of the characterized nanocomplex via half-maximum inhibitory concentration $\left(\mathrm{IC}_{50}\right)$ estimation. The MTT results illustrated that the novel nanoformulated DS-CuO complex had the strongest anticancer activity $\left(\mathrm{IC}_{50}<15 \mathrm{nM}\right)$ against breast, lung and liver cancer cells when compared to DS-Cu complex ( $\left.\mathrm{IC}_{50}>151 \mathrm{nM}\right)$, DS ( $\left.\mathrm{IC}_{50}>220 \mathrm{nM}\right), \mathrm{CuO} \mathrm{NPs}\left(\mathrm{IC}_{50}>447 \mathrm{nM}\right)$, $\mathrm{CuO}\left(\mathrm{IC}_{50}>846 \mathrm{nM}\right)$ and $\mathrm{Cu}\left(\mathrm{IC}_{50}>943 \mathrm{nM}\right)$. The calculated $\mathrm{IC}_{50}$ values of $\mathrm{DS}-\mathrm{CuO}$ NPs were $14.82 \pm 0.909,10.59 \pm 1.32,7.27 \pm 1.09$ and $6.72 \pm 0.204 \mu \mathrm{M}$ for MDA-MB 231, A549, Huh7 and HepG2 cells, respectively (Fig. 2a). At latter $\mathrm{IC}_{50}$ values, powerful anticancer effect of the nanocomplex was further verified by the dramatic alteration in the morphology of all investigated cancer cells, compared to healthy morphology of the conventional complex-treated cells (Fig. 2b). More interestingly, the estimated combination index (CI) values of DS-CuO NPs $(0.032,0.029,0.022$ and 0.022$)$ were 10 times lower than that of DS-Cu $(0.344,0.342,0.439$ and 0.435$)$, indicating a higher synergistic anticancer effect against all studied cancer cell lines (MDA-MB 231, A549, Huh7 and HepG2, respectively). Moreover, the dose reducing index (DRI) of DS in nanocomplex increased by 12.75 - to 23.86 -fold when compared to conventional complex as

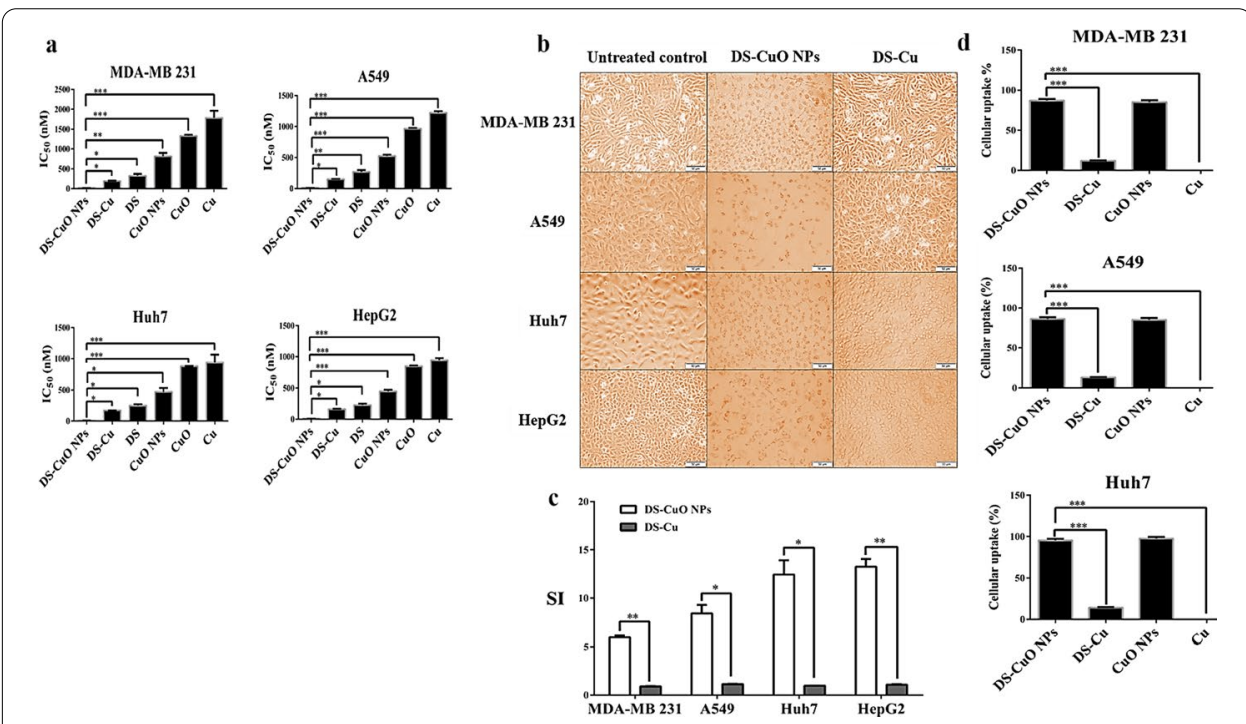

Fig. 2 Selective cancer growth inhibitory potency and cellular uptake of the tested compounds. a The $I C_{50}$ values of nanocomplex, DS-Cu and their individual components for growth inhibition (50\%) of MDA-MB 231, A549, Huh7 and HepG2 cells after $48 \mathrm{~h}$ incubation. b Morphology alterations of DS-CuO NPs- and DS-Cu-treated four cancer cell lines compared to the untreated control cells (magnification, 100 x; scale bar, 50 um). c Selectivity index (SI) values of DS-CuO NPs and DS-Cu for human cancer cell lines. $\mathbf{d}$ Cellular uptake (\%) of CuO NPs and Cu alone as well as in combination with DS after $2 \mathrm{~h}$ incubation with breast, lung and liver cancer cells, relative to the original amounts of Cu or CuO NPs. Data (mean \pm SEM), DS-CUO NPs was compared to other tested compounds and considered significantly different at $p<<0.05^{*},<0.005^{* *},<0.001^{* * *}$ 
well as $\mathrm{CuO}$ NPs was $5.829-11.98$ folds of $\mathrm{Cu}$, supporting that better synergy exists in nanocomplex.

Because the selectivity of cytotoxicity of any novel drug (DS-CuO nanocomplex) against human cancer cells is crucial, its cytotoxicity on HMNCs was assessed, in the term of $\mathrm{IC}_{50}$, to calculate SI values for each human cancer cell line. The estimated $\mathrm{IC}_{50}$ values of DS $-\mathrm{Cu}$ NPs and DS-Cu were $88.75 \pm 2.72 \mathrm{nM}$ and $176.61 \pm 3.98 \mathrm{nM}$, respectively, on HMNCs. As shown in Fig. 2c, SI values of DS-CuO NPs for MDA-MB 231, A549, Huh7 and HepG2 were 6.00, 8.48, 12.43 and 13.23, respectively, compared to $\sim 1$ in the case of DS-Cu complex for all tested cancer cell lines.

\section{High cellular uptake of DS-CuO NPs}

After $2 \mathrm{~h}$ incubation of cancer cells with the maximum safe dose, both NPs of $\mathrm{CuO}$ and DS-CuO were taken up very well $(>85 \%)$ by all investigated cancer cells compared to DS-Cu complex (12-14\%) as shown in Fig. 2d. At this experiment condition (time and dose), cellular uptake of $\mathrm{Cu}$ alone was practically undetectable and due to the fact that its intracellular transport is limited, but such complex can be enhanced its uptake.

\section{Apoptosis-mediated anticancer effect of DS-CuO NPs}

Flow cytometric analysis (Fig. 3a, b) recorded that the percentages of annexin-stained apoptotic DS-CuO NPs-treated MDA-MB 231, A549, Huh7 and HepG2 cells were $51.24 \pm 2.13 \%, 65.28 \pm 0.35 \%, 52.40 \pm 1.74 \%$ and $52.99 \pm 1.455$, respectively. Comparably, DS-Cu complex did not show either an obvious apoptotic effect (0.015-8\%), at the same used concentrations $\left(\mathrm{IC}_{50}\right)$ of DS-CuO NPs, or significant difference with the control untreated MDA-MB 231, Huh7 and HepG2 cancer cells (Fig. 3a, b). Additionally, the potent apoptotic activity of DS-CuO NPs was confirmed by investigating the EB/AOstained cells under a fluorescence microscope. This was demonstrated by the existence

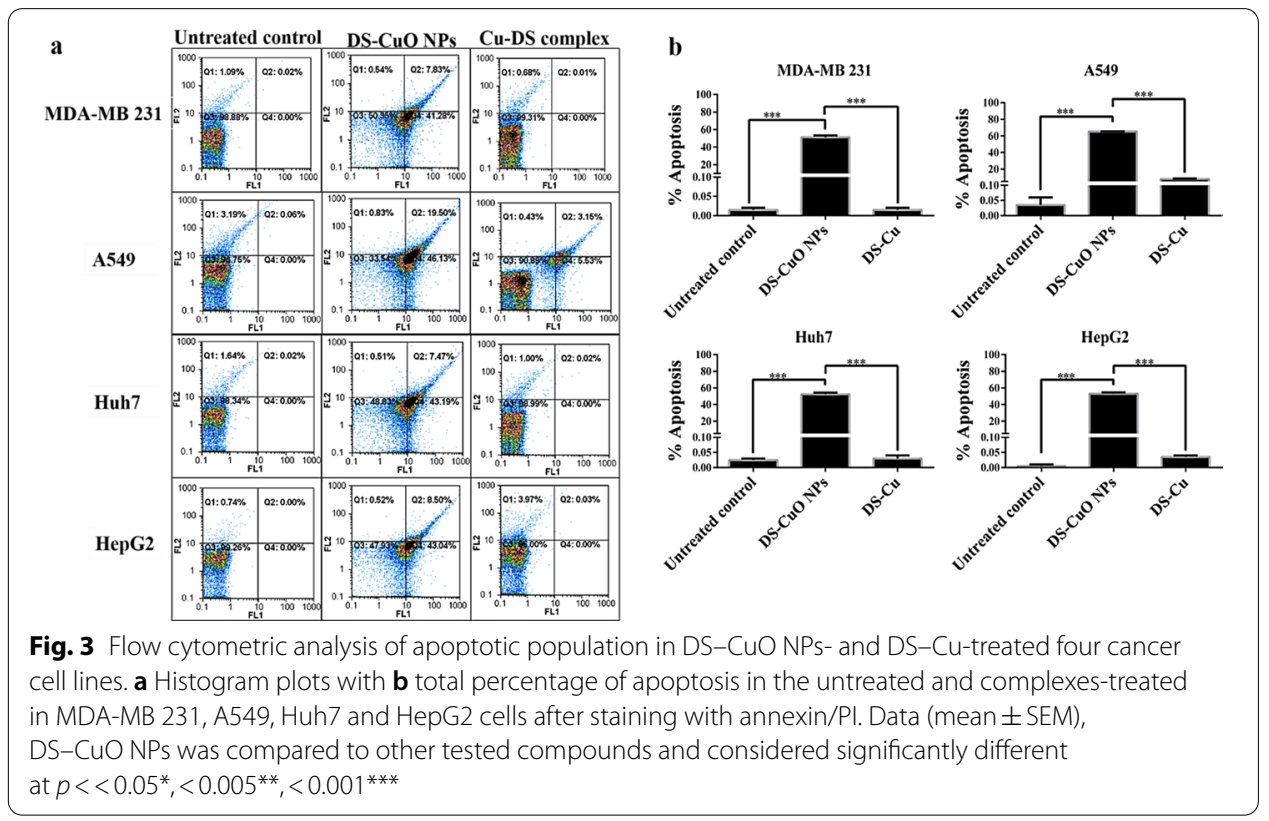


of yellow, orange and reddish orange fluorescence of apoptotic nuclei in only DS-CuO NPs-treated four cancer cell lines, while all DS-Cu-treated cells had green fluorescence nuclei like healthy untreated cancer cells (Fig. 4a). Moreover, DS-CuO NPs enhanced significantly the gene expression of main apoptosis mediator (p53) by $3.83-4.87$ folds relative to DS-Cu (Fig. 4b).

\section{Anti-metastatic potency of DS-CuO NPs}

To evaluate the anti-metastatic capability of the unique DS-CuO nanocomplex, the inhibition of wound healing was estimated in the treated breast, lung and liver cancer cells relative to the untreated cells (Fig. 5a, b). The migration inhibition \% in DS-CuO NPstreated cancer cells (58.38-78.08\%) was significantly higher than that in DS-Cu complex (17.21-26.40\%). Moreover, MMP9 which involves in basement membrane degradation to promote cell invasion, was inhibited by $35.79-52.79 \%$ in DS-CuO NPs-treated cells versus $14.29-24.44 \%$ in DS-Cu (Fig. 5c).

\section{The impact of DS-CuO NPs on key redox mediators-dependent carcinogenesis}

Reactive oxygen species play an important role in cancer initiation and progression. Thus cellular content of ROS was measured after the cancer cells were treated with the prepared DS complexes. Figure 6a demonstrated that DS-CuO NPs induced massive ROS production, relative to the untreated cells, by $23.97,26.82$ and 33.84 folds but only by 2 folds in DS-Cu-treated MDA-MB 231, A549 and Huh7 cells, respectively. Because aldehyde dehydrogenase (ALDH)1A and nuclear factor erythroid 2-related factor 2 (Nrf2) are important defenders against excessive free radicals, their inhibition by the tested complexes was assessed. Figure $6 \mathrm{~b}$ reveals that the activity of ALDH1A was highly inhibited in DS-CuO NPs-treated cells by $69.39-95.47 \%$ compared to $<30 \%$ in the case of DS-Cu complex. Also, DS-CuO NPs suppressed the transcription of Nrf2 by

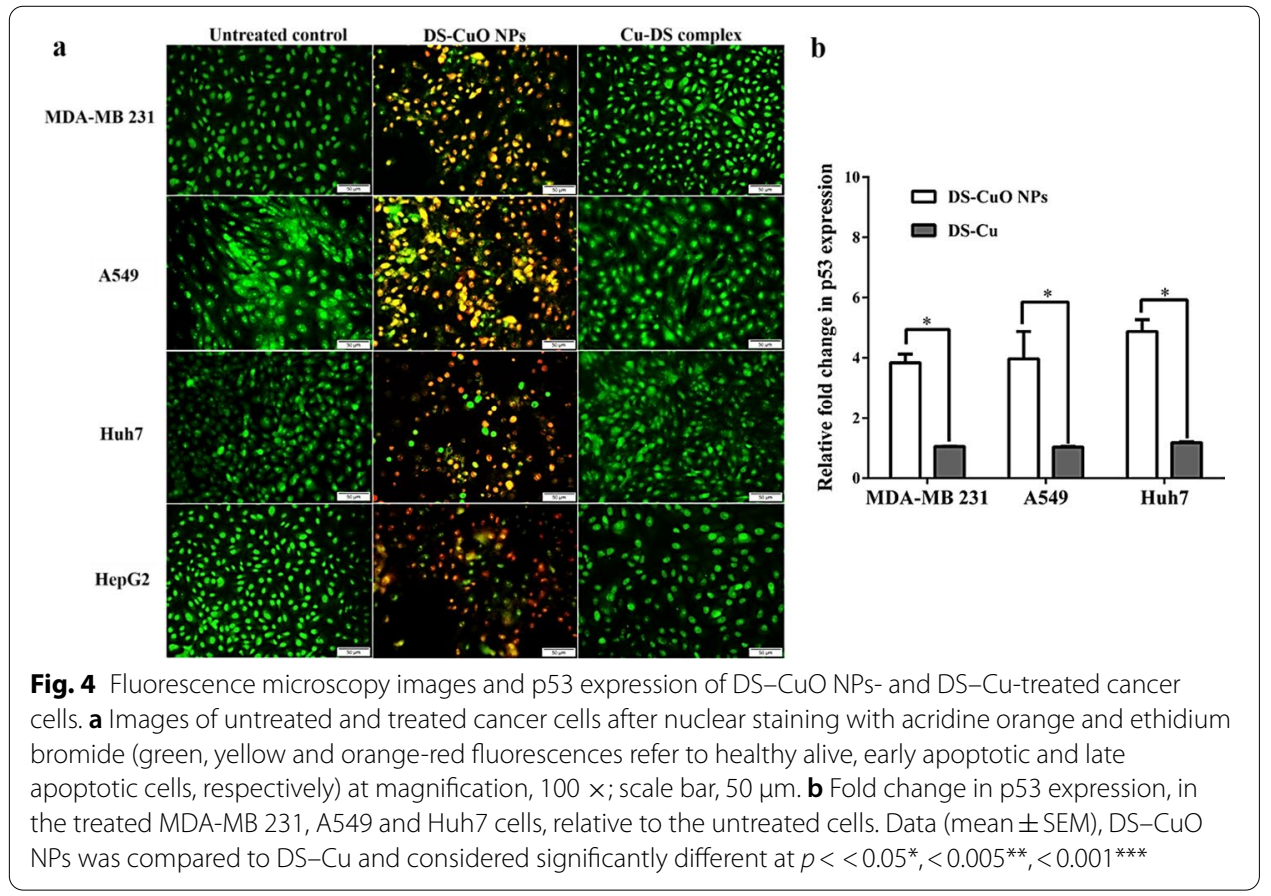




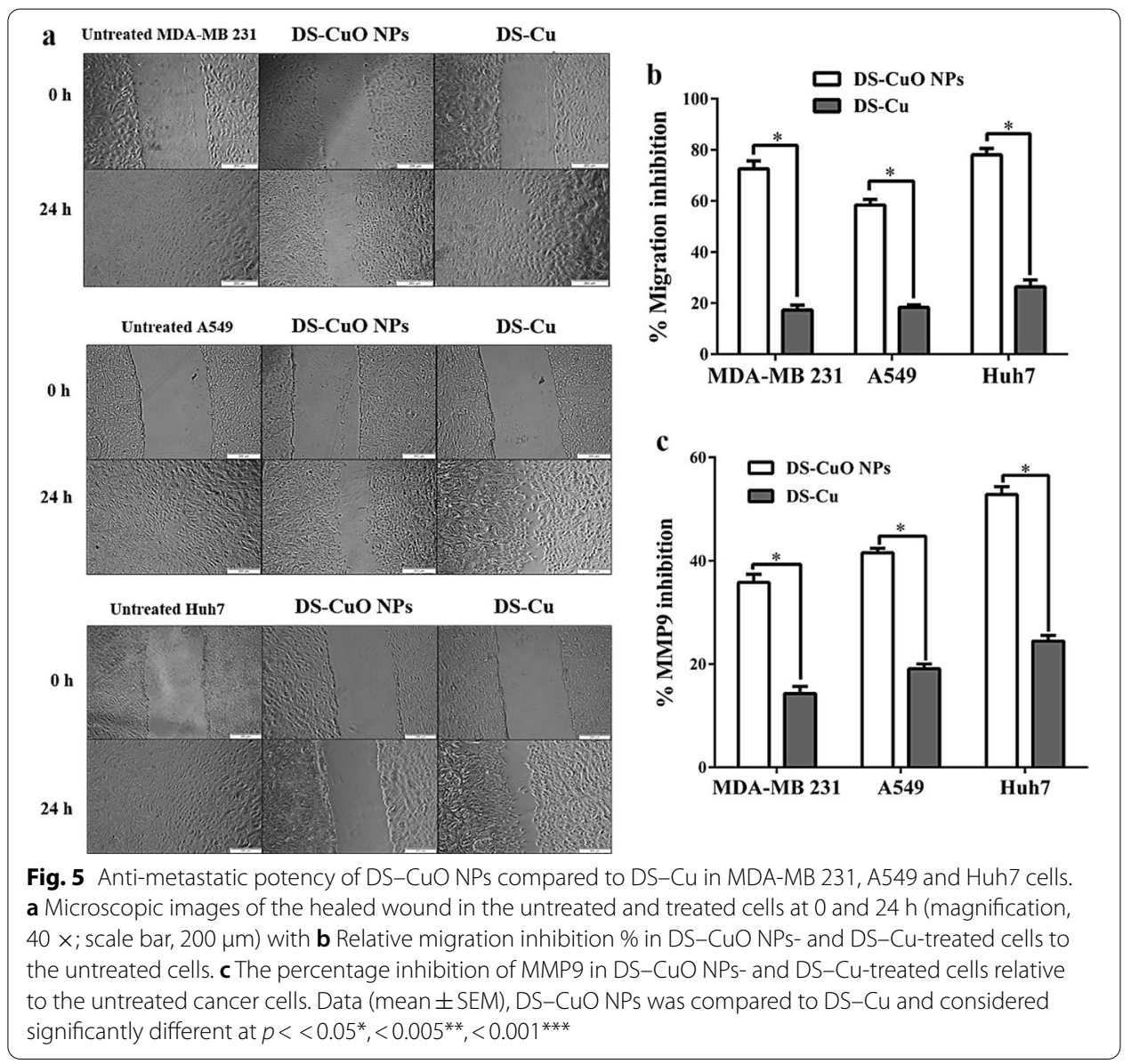

2.74, 2.49 and 2.56 folds relative to DS-Cu complex in MDA-MB 231, A549 and Huh7, respectively (Fig. 6c). ROS activate NF- $\mathrm{kB}$, one of the main transcription factors of several oncogenic genes. Figure $6 \mathrm{~d}$ demonstrates that DS-CuO NPs diminished the gene expression of NF-кB by $5.99,8.69$ and 9.80 folds, respectively, in breast, lung and liver cancer cells. Meanwhile, no significant changes were recorded in DS-Cu complex relative to the untreated cancer cells. Furthermore, immunostaining for inhibitor subunit I kappa B (ІкB) in the untreated and treated MDA-MB 231, A549 and Huh7 cells disclosed that DS-CuO NPs have a higher cellular content (55.32-76.21\%) than DS-Cu complex (8.68-21.14\%), at 14.81, 10.59 and $7.27 \mathrm{nM}$, which was not statistically different from the untreated cells (Fig. $7 \mathrm{a}, \mathrm{b})$.

\section{Discussion}

Disulfiram, FDA-approved drug, is one of the most potent broad anticancer compounds in the presence of $\mathrm{Cu}$. Unfortunately, DS and its DS-Cu complex have limited clinical applications due to their poor solubility (Wehbe et al. 2017). Thus extensive research is required to improve the bioavailability of DS-Cu. Herein, this challenge was solved, for the first time, by chelating DS to bacterially synthesized $\mathrm{CuO}$ NPs. The characterization of water soluble DS-CuO complex revealed its nanosize $(235 \mathrm{~nm})$ as well as the homogeneity and uniformity between its particles, as evidenced by its low $\mathrm{PDI}<0.15$. 


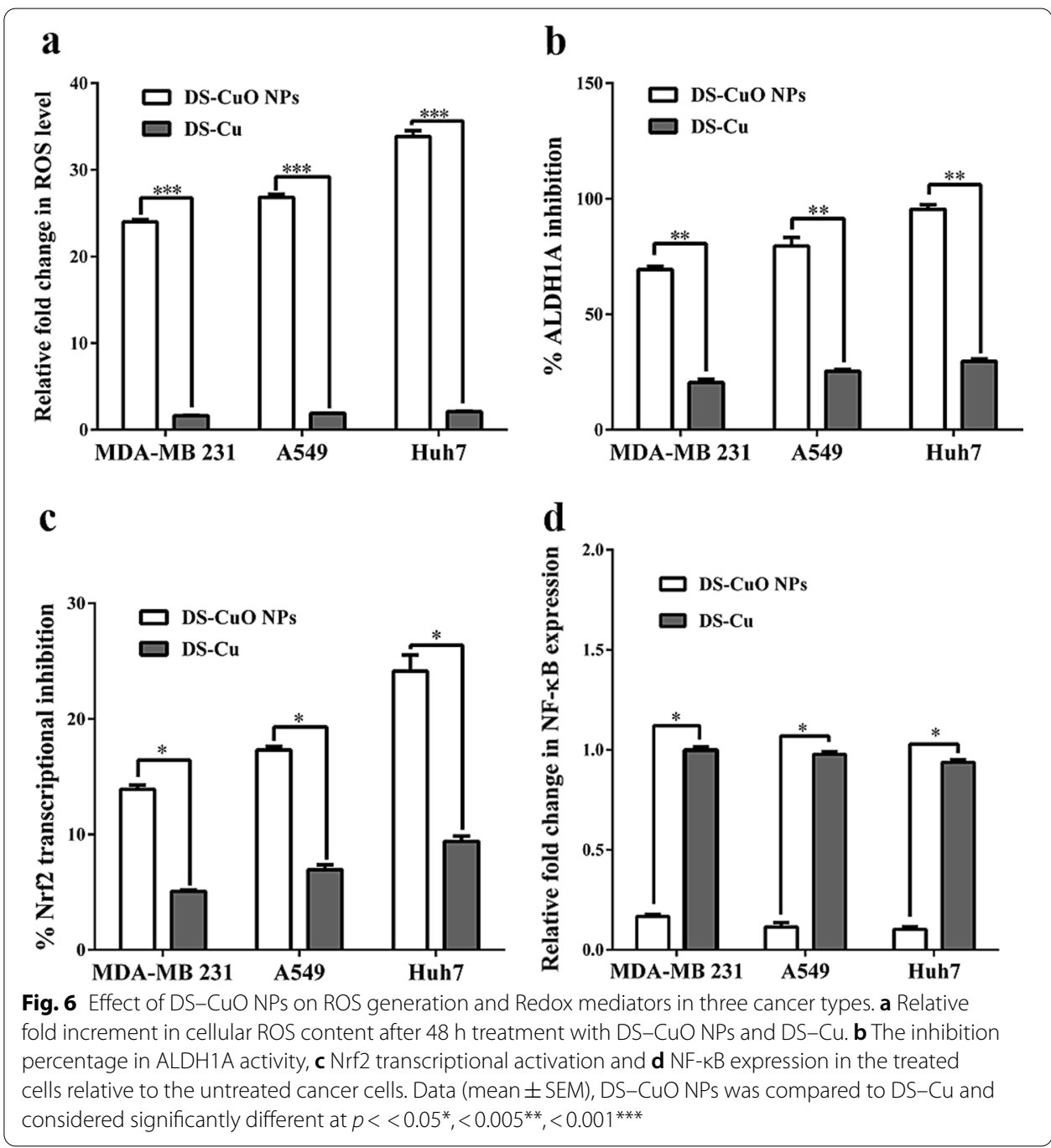

The latter and its negative charge $(-26.21 \mathrm{mV})$ proved the stability of this nanocomplex. This high negative zeta-potential value implies considerable particle repulsion, higher Brownian motion and lower aggregation tendency, all of which lead to long-term stability (Krutisova et al. 2015). The latter was practically ascertained by a negligible change in its nanosize over $72 \mathrm{~h}$ incubation in PBS/50\% FBS. These findings indicated a good stable and soluble nanoformulation of a triclinic crystalline rod-shaped DS-CuO complex (Cu thiourea sulfate hydrate).

Aside from the nanocharacterization mentioned above, higher cellular uptake of DS$\mathrm{CuO}$ NPs may correlate with better selective anticancer efficacy than DS-Cu. Besides this, the selectivity (SI) of DS-CuO NPs outperformed DS-Cu by $>6$ folds in all tested cancer cell lines. The high selectivity of DS-CuO NPs between cancer cells and MNCs may be attributed to their rod-shaped. The shape of NPs is an important determinant in cellular uptake and phagocytosis (Baranov et al. 2021). However, the large bulk of nanomedicines are spherical shaped due to their ease of processing (Ma et al. 2019). Previous studies found that rod-like NPs were less efficiently phagocytosed than sphere-shaped NPs and the particle uptake increases with particle size larger than $0.5 \mu \mathrm{m}$ (Baranov 

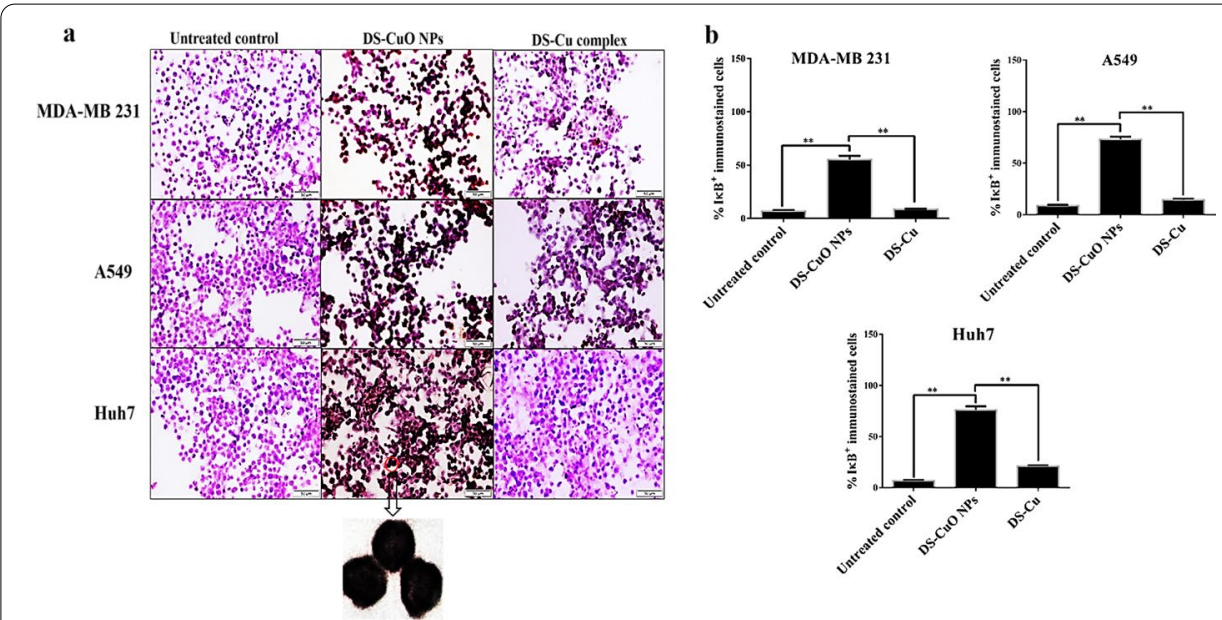

Fig. 7 Effect of DS-CuO NPs on protein level of inhibitor subunit I kappa (IK) B using immunohistochemical technique. a Immunohistochemical staining images of $\mathrm{IKB}$ in the untreated and DS-CuO NPs- and DSCu-treated MDA-MB 231, A549 and Huh7 cells (magnification, 100 x; scale bar, $50 \mu \mathrm{m}$ ) with maximum magnification for brown stained IKB ${ }^{+}$DS-CUO NPs-treated cancer cells declaring its cellular localizations in both nucleus and cytoplasm. $\mathbf{b}$ Percentage of $1 \mathrm{~KB}^{+}$-immunostained cell population in the untreated and treated MDA-MB 231, A549 and Huh7 cells. Data (mean \pm SEM), DS-CUO NPs were compared to DS-Cu and considered significantly different at $p<<0.05^{*},<0.005^{* *},<0.001^{* * *}$

et al. 2021; Zhao et al. 2017; Bohdanowicz et al. 2013). On the other hand, less rigidity and higher permeability of cancer cell membranes than normal cells could be also directly linked to the low $\mathrm{IC}_{50}$ and high SI of DS-CuO NPs in the treated cancer cell lines. Previous studies revealed that rod-shaped NPs had higher specific tumor internalization than their spherical counterparts in liver, cervical and breast cancer cells (Ma et al. 2019; Zhao et al. 2017; Barua et al. 2013). Such unusual NPs induced apoptosis in breast, lung and liver cancer cells by $>51 \%$ with $\mathrm{IC}_{50}$ values that were 10 folds lower than DS-Cu which induced apoptosis in only $\leq 8 \%$ of the cells. This potent apoptotic effect of DS-CuO NPs is associated with a stronger anti-metastatic activity than conventional complex. More importantly, the anticancer synergistic interaction between $\mathrm{DS}$ and $\mathrm{CuO}$ NPs was 10 times more powerful than that between DS and $\mathrm{Cu}$ (as proved by lower $\mathrm{CI}$ and higher DRI). The following reasons are proposed to explain the potent synergistic anticancer activity of this unconventional nanocomplex.

Based on previous studies, the main factors of the apoptotic-mediated cancer death effect of chelating complex can be summarized as excessive ROS, the formation of mixed disulfides and proteasome inhibition (Meraz-Torres et al. 2020; Liu et al. 2012). Because of its combination with $\mathrm{CuO}$ NPs, nanocomplex was 23 times more potent ROS inducer than DS-Cu (Fig. 6a) that rendering DS-CuO NPs had a higher synergistic anticancer activity. It has been reported that prooxidant activity of $\mathrm{CuO}$ NPs originated from NPs themselves and/or $\mathrm{Cu}$ ions. The latter are released following the cellular internalization of $\mathrm{CuO}$ NPs by lysosomal degradation (Fahmy and Cormier 2009). Previous findings reported that $\mathrm{CuO}$ NPs themselves can inhibit antioxidant enzymes (catalase, superoxide dismutase and glutathione reductase), generate ROS and decrease level of reduced glutathione (GSH), resulting in oxidative stress (Reddy and Lonkala 2019; Fahmy and Cormier 2009). The potent prooxidant effect of CuO NPs could be a major underlying mechanism for triggering the intrinsic and extrinsic pathways of apoptosis 
via upregulating the expression of intrinsic apoptotic mediators (cytochrome $C$, caspase 7 and 9) and activation of caspase 8, respectively (Letchumanan et al. 2021). The loss of mitochondrial membrane potential then activation of p53-mediated apoptosis were recorded in various cancer types (breast, lung and liver) treated with $\mathrm{CuO}$ NPs (Ali et al. 2020; Sharma et al. 2020; Sankar et al. 2014). Moreover, CuO NPs suppressed the expression of MMP2, MMP9 and Bcl2, while upregulated the expression of Bax and cytochrome $\mathrm{C}$ in $\mathrm{A} 549$ cells (Kalaiarasi et al. 2018). In contrast to CuO NPs, copper alone did not exert a good anticancer effect (Fig. 2a) due to its limited internalization via the copper transporter (Ctr) to sustain redox homeostasis. Despite DS enforces cellular $\mathrm{Cu}$ transport in a Ctr-independent manner (Cen et al. 2004), the uptake of CuO NPs or DS-CuO NPs were higher (Fig. 2d). This is due to their nanosizes, which allow for internalization via endocytosis, followed by lysosomal degradation and then $\mathrm{Cu}$ liberation inside the cytosol (Bulcke et al. 2016; Shang et al. 2014). Copper's potency to enhance the cytotoxic effect of DS and to act as prooxidant, via the generation of ROS and glutathione oxidation, is proportional to its cellular uptake (Chudal et al. 2020; Meraz-Torres et al. 2020; Peng et al. 2019) which was enhanced in nanocomplex-exposed cancer cells (Fig. 2a-d). Furthermore, DS causes depletion of antioxidant mediators by the irreversible oxidation of GSH and $\mathrm{NAD}(\mathrm{P}) \mathrm{H}$ as well as irreversible inhibition of ALDH (Meraz-Torres et al. 2020; Peng et al. 2019). ALDH1A is critical for protecting and maintaining cancer stem cells (tumor initiator) by scavenging a variety of highly toxic aldehydes. ALDH1A is essential for the progression, chemoresistance and invasion of several cancers, making ALDH1A inhibition as highly effective treatment strategy (Liu et al. 2012; Tomita et al. 2016). Previous research found that $\mathrm{IC}_{50}$ of DS for ALDH inhibition was 72 folds higher than that of DS in combination with $\mathrm{Cu}$, indicating that this complex strongly suppressed ALDH (Liu et al. 2012).

The ALDH1 inhibitory efficacy of DS attributes to its high affinity for thiol groups forming disulfide adducts in ALDH1 active site (Koppaka et al. 2012). This thiol affinity of DS can further disrupt the functions of vital cysteine-enriched proteins, such as MMP9 and Nrf2, which mediate metastasis and oxidative stress defense, respectively (Brar et al. 2004). Cysteine residues in Nrf2 are critical for preventing its proteasomal degradation and for its role in the transcriptional activation of antioxidant enzyme genes (He and Ma 2009). DS also oxidizes the thiol groups of mitochondrial proteins, resulting in pore opening then apoptosis induction (Cen et al. 2002). Moreover, DS forms mixed disulfides with thiol-contained transcription factors (TF) and mediates S-glutathionylation making TF negatively charged and then reducing TF binding to gene promotors. According to Brar et al. (2004), $\mathrm{Cu}$ enhanced the aforementioned process, causing TF to become more negatively charged and thus blocking TF binding activity to gene promoter such as NF- $\mathrm{kB}$ gene (Brar et al. 2004). DS-Cu impeded not only NF- $\mathrm{kB}$ expression but also its activation by inhibiting proteasome activity, which degrades ІкB from the latent cytoplasmic complex and thus prevents its nuclear translocation (Viola-Rhenalsa et al. 2018). $\mathrm{Cu}$ is essential for chelating complex to act as proteasome inhibitor, which is considered as promising anticancer agents. Previous results demonstrated that this complex inhibited the proteasome activation and induced apoptosis when the $\mathrm{Cu}$ was transported into cancer cells (Zhang et al. 2017). In accordance with our in vitro findings, the novel nanocomplex revealed a higher suppressive effect on activity MMP9 
(Fig. 5c), ALDH1A and Nrf2 and expression of NF-кB (Fig. 6) as well as ІкB degradation (Fig. 7). This suggests that TF binding and proteasome activation inhibitory effects of the typical complex were negligible at these used low doses (7-15 nM) in contrast to DS$\mathrm{CuO}$ NPs mainly due to the significant difference in their cellular uptakes.

\section{Conclusion}

In this current study, we exploited the chelating ability of DS to metal to prepare a novel nanoformulated complex with biologically synthesized $\mathrm{CuO}$ NPs using a simple and cheap method to improve the anticancer efficacy of a traditional DS complex. This novel crystalline needle-shaped complex (DS-CuO NPs) revealed acceptable nanocharacterization with good solubility and biostability in serum. Because of its nanosize, this novel complex (DS-CuO NPs) exhibited better cellular uptake in breast, lung and liver cancer cell lines compared to DS-Cu. Besides that, previous studies found that $\mathrm{CuO}$ NPs had prooxidant activity-mediated potential anticancer effect by upregulating the expression of proapoptotic genes and downregulating oncogenes, whereas $\mathrm{Cu}$ alone did not show this activity. In accordance with the current results, $\mathrm{Cu}$ had lower growth inhibitory effect than $\mathrm{CuO}$ NPs over all tested cancer cell lines (Fig. 1a). According to the current findings (nanosize, higher cellular uptake and anticancer effect of $\mathrm{CuO} \mathrm{NPs),} \mathrm{its} \mathrm{combi-}$ nation with DS, at $<15 \mathrm{nM}$, exhibited a superior synergistic anticancer effect (lower CI and higher DRI) with higher selectivity than DS-Cu against three types of cancers. This is also confirmed by higher potency of this unique nanocomplex in inducing p53-mediated apoptosis, elevating ROS and inhibiting MMP9-mediated metastasis, ALDH1A, Nrf2 activation as well as NF- $\mathrm{kB}$ expression and activation. The high inhibitory potency of DS-CuO NPs on ALDH1A-sustained CSC strength and MMP9 discloses their efficacy in preventing tumor relapse and combating cancer, even at late stage (metastasis). Hence, this novel study can meet expectations by improving the therapeutic index of DS-Cu complex via nanoformulation with biosynthesized $\mathrm{CuO}$ NPs resulting in lowering the effective anticancer dose and boosting ROS-dependent apoptotic effect by enhancing its cellular uptake. In future, in vivo studies will be needed to further investigate the anticancer efficacy of this novel nanomedicine using animal models.

\footnotetext{
Abbreviations

ALDH: Aldehyde dehydrogenase; CuO NPs: Copper oxide nanoparticles; DS: Disulfiram; ROS: Reactive oxygen species; EDX: Energy-dispersive X-ray spectrometer; IKB: Inhibitor subunit I kappa B; JCPDS: Joint Committee on Powder Driven Standards; MMPs: Matrix metallopeptidases; Nrf2: Nuclear factor erythroid 2-related factor 2; PDI: Polydispersity index; PI: Propidium iodide; SEM: Scanning electron microscope; SI: Selectivity index; Tf: Transcription factor; TEM: Transmission electron microscope; XRD: X-ray diffractometer.
}

\section{Supplementary Information}

The online version contains supplementary material available at https://doi.org/10.1186/s12645-021-00097-5.

Additional file 1: Figure S1. Zetasizer-generated data for CuO NPs and DS-CUO NPs. a Size of CuO NPs and DSCuO NPs. b Zeta potential of CuO NPs and DS-CuO NPs.

Acknowledgements

Not applicable.

Authors' contributions

MMA-S put idea and designed this current study, performed most of the experiments, analyzed data as well as wrote and revised the manuscript. MME conducted the biosynthesis of CuO NPs, wrote methodology and result parts as 
well as interpreted analyses that related to CuO NPs and their characterization. All authors read and approved the final manuscript.

\section{Funding}

Not applicable.

\section{Availability of data and materials}

The generated and analyzed data during the current study is supplied in this manuscript and is readily available from the corresponding authors upon reasonable request.

\section{Declarations}

Ethics approval and consent to participate

Not applicable.

\section{Consent for publication}

Not applicable.

\section{Competing interests}

The authors state that they do not have any financial or non-financial competing interests.

\section{Author details}

${ }^{1}$ Medical Biotechnology Department, Genetic Engineering and Biotechnology Research Institute (GEBRI), City of Scientific Research and Technological Applications (SRTA-City), New Borg El-Arab City, Alexandria 21934, Egypt. ${ }^{2}$ Environmental Biotechnology Department, Genetic Engineering and Biotechnology Research Institute (GEBRI), City of Scientific Research and Technological Applications (SRTA-City), New Borg El-Arab City, Alexandria 21934, Egypt.

Received: 28 April 2021 Accepted: 28 August 2021

Published online: 06 September 2021

\section{References}

Ali K, Saquib Q, Ahmed B, Siddiqui MA, Ahmad J, Al-Shaeri M et al (2020) Bio-functionalized CuO nanoparticles induced apoptotic activities in human breast carcinoma cells and toxicity against Aspergillus flavus: an in vitro approach. Process Biochem 91:387-397

Almond JB, Cohen GM (2002) The proteasome: a novel target for cancer chemotherapy. Leukemia 16:433-443

Baranov MV, Kumar M, Sacanna S, Thutupalli S, van den Bogaart G (2021) Modulation of immune responses by particle size and shape. Front Immunol 11:607945

Barua S, Yoo JW, Kolhar P, Wakankar A, Gokarn YR, Mitragotri S (2013) Particle shape enhances specificity of antibodydisplaying nanoparticles. Proc Natl Acad Sci USA 110:3270-3275

Bohdanowicz M, Grinstein S (2013) Role of phospholipids in endocytosis, phagocytosis, and macropinocytosis. Physiol Rev 93(1):69-106

Brar SS, Grigg C, Wilson KS, Holder WD, Dreau D, Austin C et al (2004) Disulfiram inhibits activating transcription factor/ cyclic AMP-responsive element binding protein and human melanoma growth in a metal-dependent manner in vitro, in mice and in a patient with metastatic disease. Mol Cancer Ther 3(9):1049

Bulcke F, Dringen R (2016) Handling of copper and copper oxide nanoparticles by astrocytes. Neurochem Res 41:33-43

Cen D, Brayton D, Shahandeh B, Meyskens FL Jr, Farmer PJ (2004) Disulfiram facilitates intracellular Cu uptake and induces apoptosis in human melanoma cells. J Med Chem 47:6914-6920

Cen D, Gonzalez I, Buckmeier JA, Kahlon RS, Tohidian NB, Meyskens FL (2002) Disulfiram induces apoptosis in human melanoma cells: a redox-related process. Mol Cancer Ther 1:197-204

Chang Y, Wu F, Pandey NK, Chudal L, Xing M, Zhang X et al (2020) Combination of disulfiram and copper-cysteamine nanoparticles for an enhanced antitumor effect on esophageal cancer. ACS Appl Bio Mater 3:7147-7157

Chen W, Yang W, Chen P, Huang Y, Li F (2018) Disulfiram copper nanoparticles prepared with a stabilized metal ion ligand complex method for treating drug-resistant prostate cancers. ACS Appl Mater Interfaces 10(48):41118-41128

Chudal L, Pandey NK, Phan J, Johnson O, Lin L, Yu H et al (2020) Copper-cysteamine nanoparticles as a heterogeneous fenton-like catalyst for highly selective cancer treatment. ACS Appl Bio Mater 3(3):1804-1814

Duan L, Shen H, Zhao G, Yang R, Cai X, Zhang L et al (2014) Inhibitory effect of Disulfiram/copper complex on non-small cell lung cancer cells. Biochem Bioph Res Co 446:1010-1016

Eltarahony M, Zaki S, Abd-El-Haleem D (2018) Concurrent synthesis of zero-and one-dimensional, spherical, rod-, needleand wire-shaped CuO nanoparticles by Proteus mirabilis 10B. J Nanomater 2018:1-14

Eltarahony M, Abu-Serie M, Hamad H, Zaki S, Abd-El-Haleem D (2021) Unveiling the role of novel biogenic functionalized CuFe hybrid nanocomposites in boosting anticancer, antimicrobial and biosorption activities. Sci Rep 11:7790

Fahmy B, Cormier SA (2009) Copper oxide nanoparticles induce oxidative stress and cytotoxicity in airway epithelial cells. Toxicol in Vitro 23(7):1365-1371

Ferrante A, Thong Y (1980) Optimal conditions for simultaneous purification of mononuclear and polymorphonuclear leucocytes from human blood by the Hypaque-Ficoll method. J Immunol Methods 36:109-117

He X, Ma Q (2009) NRF2 cysteine residues are critical for oxidant/electrophile-sensing, Kelch-like ECH-associated protein-1-dependent ubiquitination-proteasomal degradation, and transcription activation. Mol Pharmaco 76(6):1265-1278 
Kalaiarasi A, Sankar R, Anusha C, Saravanan K, Aarthy K, Karthic S et al (2018) Copper oxide nanoparticles induce anticancer activity in A549 lung cancer cells by inhibition of histone deacetylase. Biotechnol Lett 40:249-256

Koppaka V, Thompson DC, Chen Y, Ellermann M, Nicolaou KC, Juvonen RO et al (2012) Aldehyde dehydrogenase inhibitors: a comprehensive review of the pharmacology, mechanism of action, substrate specificity, and clinical application. Pharmacol Rev 64(3):520-539

Krutisova T, Hejna J, Pekar M (2015) Nanoparticles formed by selfassembly of negatively charged hyaluronan and cationic surfactant. NanoCon 18:10-16

Letchumanan D, Sok SPM, Ibrahim S, Nagoor NH, Arshad NM (2021) Plant-based biosynthesis of copper/copper oxide nanoparticles: an update on their applications in biomedicine, mechanisms, and toxicity. Biomolecules 11:564

Liu P, Brown S, Goktug T, Channathodiyil P, Kannappan V, Hugnot J-P et al (2012) Cytotoxic effect of disulfiram/copper on human glioblastoma cell lines and ALDH-positive cancer-stem-like cells. Brit J Cancer 107:1488-1497

Ma C, Zhang J, Zhang T, Sun H, Wu J, Shi J, Xie Z (2019) Comparing the rod-like and spherical bodipy nanoparticles in cellular imaging. Front Chem 7:765

Meng X, Jia K, Sun K, Zhang L, Wang Z (2021) Smart responsive nanoplatform via in situ forming disulfiram-copper ion chelation complex for cancer combination chemotherapy. Chem Eng J 415:128947

Meraz-Torres F, Ploger S, Garbe C, Niessner H, Sinnberg T (2020) Disulfiram as a therapeutic agent for metastatic malignant melanoma —old myth or new logos? Cancers 12:3538

Mosmann T (1983) Rapid colorimetric assay for cellular growth and survival: application to proliferation and cytotoxicity assays. J Immunol Methods 65(1-2):55-63

Najlah M (2021) Drug repurposing supported by nanotechnology: a promising strategy to fight cancer. Ther Deliv 12(4):267-269

Peng X, Pan Q, Zhang B, Wan S, Li S, Luo K et al (2019) Highly stable, coordinated polymeric nanoparticles loading copper (ii) diethyldithiocarbamate for combinational chemo/chemodynamic therapy of cancer. Biomacromol 20(6):2372-2383

Reddy ARN, Lonkala S (2019) In vitro evaluation of copper oxide nanoparticle-induced cytotoxicity and oxidative stress using human embryonic kidney cells. Toxicol Ind Health 35(2):159-164

Sankar R, Maheswari R, Karthik S, Shivashangari KS, Ravikumar V (2014) Anticancer activity of Ficus religiosa engineered copper oxide nanoparticles. Mater Sci Eng C Mater Biol Appl 44:234-239

Shang L, Nienhaus K, Nienhaus GU (2014) Engineered nanoparticles interacting with cells: size matters. J Nanobiotechnol 12(5):5

Sharma M, Sharma A, Majumder S (2020) Synthesis, microbial susceptibility and anti-cancerous properties of copper oxide nanoparticles—review. Nano Express. 1:012003

Sung H, Ferlay J, Siegel RL, Laversanne M, Soerjomataram I, Jemal A, Bray F. Global cancer statistics 2020: GLOBOCAN estimates of incidence and mortality worldwide for 36 cancers in 185 countries. CA Cancer J Clin. 2021;0:1-41.

Tomita H, Tanaka K, Tanaka T, Hara A (2016) Aldehyde dehydrogenase 1 A1 in stem cells and cancer. Oncotarget 7(10):11018-11032

Viola-Rhenalsa M, Patelb KR, Jaimes-Santamariaa L, Wub G, Liuc J, Dou QP (2018) Recent advances in antabuse (disulfiram): the importance of its metal-binding ability to its anticancer activity. Curr Med Chem 25(4):506-524

Wang L, Chai X, Wan R, Zhang H, Zhou C, Xiang L et al (2020) Disulfiram chelated with copper inhibits the growth of gastric cancer cells by modulating stress response and Wnt/b-catenin signaling. Front Oncol 10:595718

Wehbe M, Anantha M, Shi M, Leung AW, Dragowska WH, Sanche L et al (2017) Development and optimization of an injectable formulation of copper diethyldithiocarbamate, an active anticancer agent. Int J Nanomed 12:4129-4146

Xu Y, Zhou Q, Feng X, Daia Y, Jianga Y, Jiang W et al (2020) Disulfiram/copper markedly induced myeloma cell apoptosis through activation of JNK and intrinsic and extrinsic apoptosis pathways. Biomed Pharmacother 126:110048

Zhang Z, Wang H, Yan M, Wang H, Zhang C (2017) Novel copper complexes as potential proteasome inhibitors for cancer treatment (review). Mol Med Rep 15:3-11

Zhao J, Lu H, Wong S, Lu M, Xiaob P, Stenzel MH (2017) Influence of nanoparticle shapes on cellular uptake of paclitaxel loaded nanoparticles in 2D and 3D cancer models. Polym Chem 8:3317-3326

\section{Publisher's Note}

Springer Nature remains neutral with regard to jurisdictional claims in published maps and institutional affiliations.

Ready to submit your research? Choose BMC and benefit from:

- fast, convenient online submission

- thorough peer review by experienced researchers in your field

- rapid publication on acceptance

- support for research data, including large and complex data types

- gold Open Access which fosters wider collaboration and increased citations

- maximum visibility for your research: over $100 \mathrm{M}$ website views per year

At BMC, research is always in progress.

Learn more biomedcentral.com/submissions 